\title{
Research on Emotional Comfort Products Based on Innovative Design Thinking: Take Digital Aid-Sleeping Products for An Example*
}

\author{
Linlin Liu $^{\dagger 1, ~ a ~}$, Yiren Zhang ${ }^{1, b}$, Zhiyuan Zhang, c \\ ${ }^{1}$ School of Art and Design Tianjin University of Science \& Technology, Tianjin, 300000, China
}

\begin{abstract}
The fast pace and great pressure of modern life have made people's psychological problems more and more serious. The outbreak of COVID-19 at the end of 2019 has accelerated the development of depression, anxiety, nervous tension and other emotions in all aspects. In severe cases, it leads to insomnia. In this paper, the impact of the epidemic on people's psychology is extensively investigated by innovative thinking. Based on the current design status of existing emotional soothing products, this article summarizes the development trends as well as the shortcomings of sleep aid products, and tries to use new technologies and materials to provide new solutions to problems for people with insomnia. Through the design of digital sleep aid products, modern technology is used to meet the practical needs of modern people and to care for the targeted insomniac. $\cdot$ Human-centered computing
\end{abstract}

\section{Introduction}

In December 2019 after the outbreak of COVID-19 in Wuhan, China, the outbreak spread rapidly in the domestic provinces and cities, the sudden public crisis is not only a serious threat to public safety of life, also bring huge psychological impact to the people, for example, panic, anxiety, worry, etc[1]. More and more people are in a state of high tension for a long time and are under tremendous mental pressure, resulting in depression, irritability, restlessness, tension and other bad emotions, resulting in neurasthenia symptoms, and then leading to sleep disorders[2]. Therefore, how to help the people who suffer from insomnia due to the pandemic is a question worthy of attention and thinking.

\section{Literature of Emotional Problems Caused by Epidemic}

Affected by the COVID-19, people have more or less psychological stress. Psychological stress means that humans perceive themselves as being stimulated by a certain stressful or unfavorable environment, the process of psychological and physiological reflexive adaptation or inadaptability caused by cognitive evaluation and countermeasures[3]. The COVID-19 has the characteristics of suddenness, strong contagion, and wide spread. It is a huge impact on the entire social population (such as ordinary residents, quarantined people, confirmed patients, suspects, close contact with medical staff, etc.)
Stress[4]. Studies have shown that stress can cause anxiety, depression, and sleep disorders[5].

Under the influence of the pandemic, the reasons for the public's psychological problems and behavioral reactions can be roughly divided into two categories: directly caused by the pandemic and indirectly caused by the pandemic. Directly: At present, the epidemic situation in my country has been well controlled, but there are still many hidden dangers, such as the frequent occurrence of imported cases from abroad, the risk of transmission of asymptomatic infections, etc. At the same time, there are often rumors on social media that cause fear among the masses, the public is prone to psychological and emotional problems such as panic and nervousness[3]. Indirectly: China has adopted tough measures such as close the city, suspension of work, and prohibition of going out to control the epidemic, causing many people to lose their sources of income and causing family conflicts. Pressure from family relationships and economic aspects causes people to produce negative emotions such as anxiety and depression.

The most direct symptoms of panic, nervousness, anxiety, and depression are insomnia. According to the "2019 China Sleep Index Report", the "2020 White Paper on Chinese Residents Sleep During the National Home Stay", and Ali Health data, now more than 300 million people across the country have a sleep disorder and the "younger" trend obviously, the pandemic exacerbates the situation. People's time delay for 2 to 3 hours of sleep, search volume has increased by $50 \%$ for sleep problems. Both sleep aid products and sleep-related health products sales have increased significantly. According to data from 
Tmall.com and JD.com, from January to September 2019, the sales of melatonin increased by $57 \%$ year-on-year, and the sales of smart mattress products increased by $200 \%$ year-on-year, the market size of sleep industry is expected to reach more than 400 billion yuan this year, and it will exceed one trillion yuan in 2030. This shows the severity of current sleep problems and the necessity for the development of emotional soothing products.

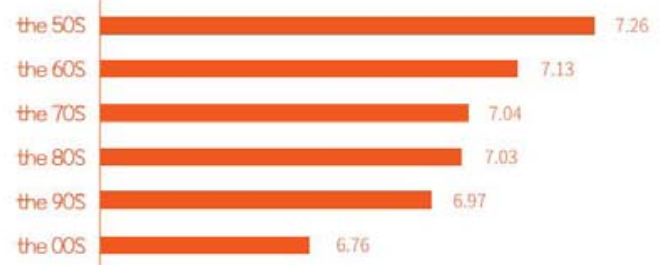

Figure 1: Sleep time for people of all ages(hours)

\section{Research on Current Situation of Emotional Comfort Products}

\subsection{Analysis of Emotional Emotional Comfort Products}

At present, the common emotional soothing products on the market include soothing dolls, soothing speakers, decompression toys, and massage equipment. In the following, 10 sample products are selected for each of the four types of products for systematic investigation and classification, and their advantages, disadvantages and functional characteristics are analyzed.

\section{Soothing dolls}

-Form: Plush doll.

-Characteristic: 1 . The shapes are mostly cute animals such as rabbits, bears and sheep; 2 . The material is mostly plush, and the filling is PP cotton and down cotton; 3 . Warm colors are concentrated in beige, coffee, sky blue, pink and goose yellow.

-Price: The imported price range is $¥ 100-300$, and the domestic price is below $¥ 100$.

-Sales volume: Average monthly sales are around 1,000 .

-Advantage: The shape is cute, not easy to be damaged, low cost and high profit.

-Disadvantage: Targeting a single population, single function, and limited actual effect.

-Function: The user is accompanied by a soft touch to provide psychological comfort.

\section{Soothing speakers}

-Form: Bluetooth speaker.

-Characteristic: 1 . Mostly include atmosphere lighting function; 2. Minimal shape; 3 . Small size.

-Price: $¥ 159-1099$, the price is greatly affected by brand awareness.

-Sales volume: The average monthly sales for prices below 300 are $300+$; the average monthly sales for prices above 300 are less than 50 .

-Advantage: Multiple functions are more superimposed, and the relaxing effect is good.

-Disadvantage: It is not much different from ordinary speakers and is not convenient to carry.

-Function: By playing light music or white noise and soft lighting to achieve the effect of soothing the user's emotions.

Decompression toys

-Form: Squeeze toy, educational toy, fidget Spinner, etc.

-Characteristic: 1 . The price is cheap; 2 . Very small size.

-Price: $¥ 0.5-85$

-Sales volume: Average monthly sales are around 1,500 .

-Advantage: It can be carried with you, soothing effect is direct and effective.

-Disadvantage: Easy to lose and dirty, safety cannot be guaranteed, single function.

-Function: Relax your emotions by kneading, squeezing objects, or focusing on cracking the mechanism.

Massage equipment

-Form: Massage pillow, leg massager, waist, neck against the instrument, massage chairs, etc.

-Characteristic: 1 . The price is expensive; 2 . Intelligent 3. Most of them need to be plugged in; 4. There are multiple massage methods such as beating, heating and electrotherapy.

-Price: The price range of massage chairs is $¥ 2000$ 8000 , and the price range of massage devices is $¥ 200-700$.

-Sales volume: The average monthly sales of massage chairs are 2000+, and the average monthly sales of massage devices are $3000+$.

-Advantage: It is directly effective for body relaxation.

-Disadvantage: It is expensive, not easy to carry, and can only relax the body.

-Function: By massaging the user's body, it can relieve muscle tension and pain.

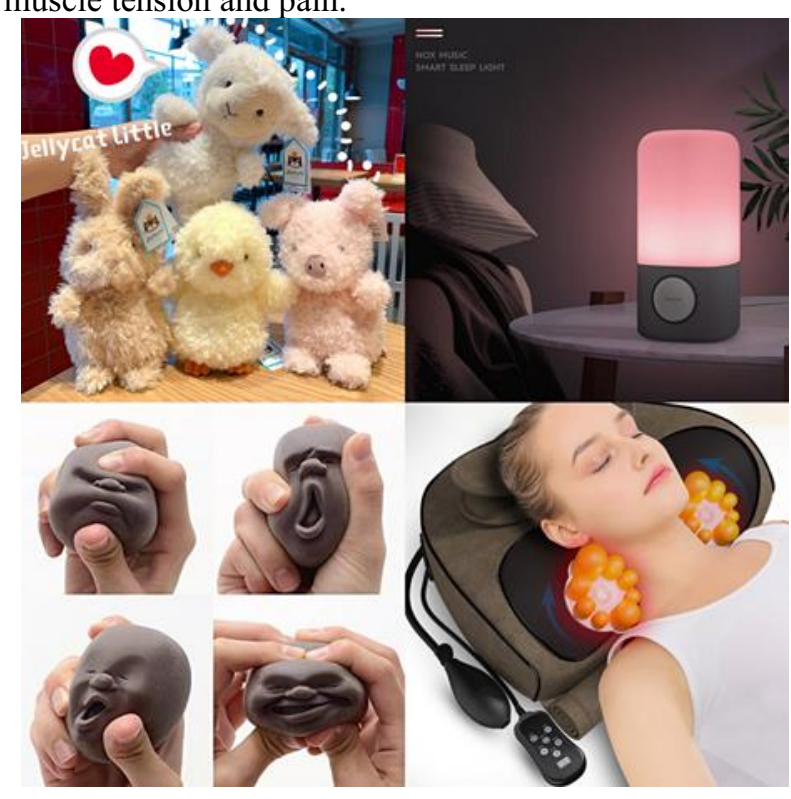

Figure 2: Soothing dolls, soothing speakers, decompression toys, massage equipment

It can be concluded that the existing emotional soothing products generally have the problem of single problem-solving methods and inability to truly provide effective psychological intervention for users. Moreover, 
powerful products are expensive, and people who are already anxious due to economic problems cannot afford them, making the problem an endless loop. Through analysis, it is found that most of the products that relieve emotions are related to helping people sleep, and the purpose is to allow users to fall asleep smoothly, sleeping smoothly plays a very important role in people's psychological adjustment.

\subsection{Analysis of Aid-Sleeping Products}

At present, there are many types of products on the market that help people sleep, including smart hardware products that mainly detect sleep data and auxiliary sleep products that make people fall asleep through external stimuli. In addition, there are sleep-related wearable products, such as various eye masks, ear muffs, earplugs made of new materials, pillows and smart mattresses, and various health-care drugs. Traditional sleep night lamps, essential oil aromatherapy and other ornamental sleep aid products play a very limited role. Wearable sleep aid products such as shade goggles and noise-reducing earplugs also have the problem of making people feel uncomfortable during sleep, and most of them cannot really achieve the sleep aid effect. At the same time, in terms of price, smart detection sleep aid products are expensive, and most people are skeptical about the sleep aid effects of sleep aid products and will not spend a lot of money on them. Earplugs, earmuffs, and eye masks are low-priced, but they only solve a certain problem. The role of the eye mask is to isolate light and provide a dark environment for sleepers. The function of earmuffs is to prevent sound from entering the ears and prevent noise from affecting people's sleep. The use of a single product does not significantly improve the problem.
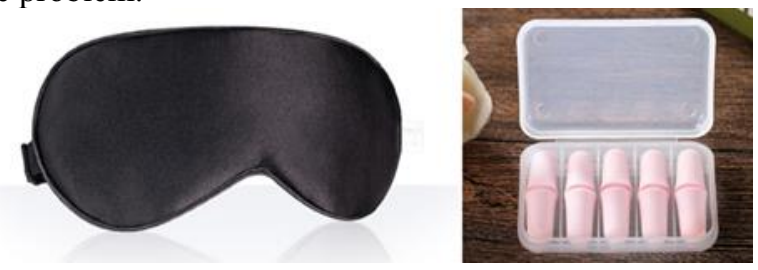

Figure 3: Existing aid-sleeping products

The increase in people's demand makes the market expand, the competition is fierce, and the design of related products is becoming more and more messy. The design of sleep aid products should form the most suitable ergonomic data for people's sleep by studying people's sleep habits and sleep states, and use the size requirements in product design to form products that are more conducive to people's sleep. By changing people's sensory experience during sleep and the external environment during sleep, it helps people with difficulty falling asleep quickly enter the state of sleep. Combine people and products, people and environment, products and environment organically to form a set of sleep aid product systems that are conducive to people's sleep.

In summary, the level of development of sleep aid products cannot be compared with its huge market demand. Especially under the special circumstances of epidemics, there is an urgent need to produce sleep aid products that meet the actual needs of modern people.

\section{Research on Development Factors of Aid-Sleeping Products}

According to the research on the behavioral and psychological characteristics of people with difficulty sleeping in the epidemic, according to the physiological and psychological characteristics of people with different degrees of sleeping difficulty, the safety and comfort factors of sleep aid products have been fully considered, in order to promote the healthy development of people with sleep difficulties.

Electronic products have radiation problems, which are not conducive to health for sleepers who use them for a long time. Therefore, the product is positioned as a nonelectronic wearable sleep aid product that uses traditional technology and environmentally friendly materials. Take the eye mask as an example, and perform the following aspects Analysis.

\subsection{Material, Color, Shape}

In terms of materials, in view of the current status of sleep aid products, considering the safety of sleep aid products and the psychological factors of users, soft and breathable skin-friendly materials such as cotton, linen and sponge are selected. It is worth noting that the material should be durable, washable, and can be used repeatedly without causing waste and pollution.

In terms of colors, we should try our best to use warm colors that make people feel warm and stable. Combined with the current epidemic situation, PANTONG 9464C safety blue can be used, which is a comfortable and safe medical representative color.

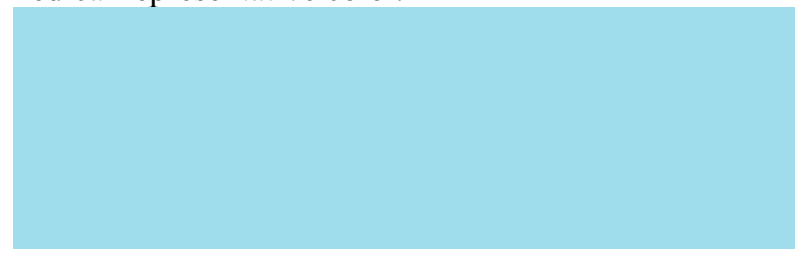

Figure 4: PANTONG 9464C safety blue

In terms of product shape, product design should fully integrate the principles of ergonomics and color psychology. The existing products are bulky, singlefunction, using earmuffs, users can only lie on their backs instead of on their sides, a simplified design is needed to solve the drawbacks of existing products. According to the ergonomic size research and the size data of the contact part between the person and the sleep aid in the sleep environment, designing a sleep aid product that meets the interpersonal size requires extensive research and summary of relevant data, as shown in Table 1 . The data comes from "Head-face dimensions of adults". 
Table 1: Face size data related to eye mask design (mm)

\begin{tabular}{|c|c|c|c|c|}
\hline & $\begin{array}{c}\text { Male } \\
\text { Average }\end{array}$ & $\begin{array}{c}\text { Male } \\
\text { Standard } \\
\text { Deviation }\end{array}$ & $\begin{array}{c}\text { Female } \\
\text { Average }\end{array}$ & $\begin{array}{c}\text { Female } \\
\text { Standard } \\
\text { Deviation }\end{array}$ \\
\hline Face Width & 143 & 3.90 & 136 & 3.71 \\
\hline $\begin{array}{c}\text { Distance of } \\
\text { Both Ears }\end{array}$ & 180 & 5.05 & 169 & 3.59 \\
\hline $\begin{array}{c}\text { Nasal } \\
\text { Height }\end{array}$ & 51 & 2.54 & 48 & 1.74 \\
\hline $\begin{array}{c}\text { Distance of } \\
\text { Canthus }\end{array}$ & 98 & 2.05 & 96 & 2.20 \\
\hline $\begin{array}{c}\text { Inner Width } \\
\text { of Both Eyes }\end{array}$ & 35 & 1.39 & 31 & 1.21 \\
\hline $\begin{array}{c}\text { Distance } \\
\text { Between } \\
\text { Ear and } \\
\text { Cheekbone }\end{array}$ & 36 & 1.14 & 35 & 1.09 \\
\hline $\begin{array}{c}\text { Distance } \\
\text { Between } \\
\text { Ear and } \\
\text { Root of Nose }\end{array}$ & 122 & 1.94 & 117 & 2.68 \\
\hline
\end{tabular}

Through the ergonomic data analysis of the human head and face, and referring to the size of existing headwear products, we have arrived at the size of this sleep aid product. The advantage of this product is that it can be expanded and contracted, and can be used by people with different head sizes. In the natural state, the distance between the ears is $16.5 \mathrm{~cm}$, which can be expanded to $20.5 \mathrm{~cm}$. The internal front and rear distance is adjustable, the shortest is $15.5 \mathrm{~cm}$ and the longest is 17.5 $\mathrm{cm}$. The height of the product is $17 \mathrm{~cm}$ and the inclination angle is $15^{\circ}$ to better fit the face. Taking into account the better sound insulation effect, the product should not be too thin. The thickness of the product is $3 \mathrm{~cm}$, leaving enough space for filling and ensuring the comfort when lying on the side.

\subsection{Function}

Aid-sleeping products need to have a good function of regulating the sleeping environment, can block light, reduce noise, bring users a comfortable sleeping environment, and promote users to sleep quickly. This should be the basic function of eye masks.

At the same time, according to investigations and studies, white noise has the function of helping people sleep. The frequency of this sound is just identifiable by humans and is uniform in each frequency band. This feature of white noise can cancel out other noises in the environment. People in a white noise environment can ignore the stimulation of noisy noise from the outside world, so the Bluetooth headset function can be added. After investigation, the current sleep aid products on the market have a single function, and there are few products that combine eye masks and ear masks, so the two functions can be combined, as shown in Figure 5.

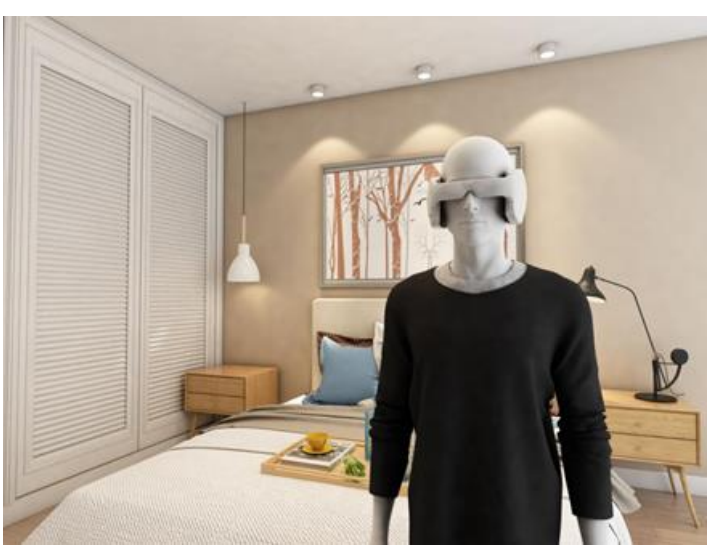

Figure 5: Design of sleep aid products combining eyemuffs and earmuffs

\section{Conclusion}

With the rapid development of society, the pace of people' s lives has gradually accelerated. The tremendous pressure has caused more and more people to have emotional problems. The outbreak at the end of 2019 has greatly exacerbated this situation. The most direct behavioral manifestation of emotional problems is insomnia. "How to make modern people sleep well under the epidemic" has gradually become a hot issue and topic in the current society, and sleep aid products have attracted more and more attention from the market and people. The variety of sleep aid products available on the market cannot properly address people's needs, which gives the related products great room for development. Designers should start from the perspective of users, comprehensively consider all kinds of data, fully explore the potential needs of the audience, and achieve the goal of truly solving problems for patients with sleep disorders, thereby affecting people's quality of life to a higher level.

\section{REFERENCES}

1. Chen, B.J and Yuan, Y(2020). The emotional state, development trend, source and impact of college students in the early stage of the COVID-19. Chinese Journal of Health Psychology, 28(11), 1646-1654.

2. Cong, J(2017). Evaluation of the influence of psychological nursing on the unhealthy mood and satisfaction of neurasthenia. Guide of China Medicine, 15(22), 203-204.

3. Cheng, Y.L and Chen,D(2020). Analysis of psychology and sleep status of general practitioners participating in epidemic prevention and control during the COVID-19. Chinese Journal of General Practice, 06(11), 1879-1883.

4. Anben, P.Z. Stress response and response to the epidemic. Tianjin Daily,2020-02-16(003).

5. OTSUKA Y, KANEITA Y, ITANI O,et al(2017). Relationship between stress coping and sleep disorders among the general Japanese population: a nationwide representative survey. Sleep Med, $37: 38-45$. 
6. Wu,E and Sui, X.B(2020). The management and guidance of the public's psychological emotions in major epidemics: taking the COVID-19 as an example. Health Research, 40(04), 361-364. 